\title{
Determination of the parameters of the recovery systems of heat potentials of streams of the gas-steam media
}

\author{
Oleksandr Shevchenko, Anatolii Sokolenko, Oleg Stepanets, Sergii But
}

National University of food Technologies, Kyiv, Ukraine

Keywords:
Recovery
Heat
Gas
Steam
Liquid
Condensation

Article history:

Received

12.09.2018

Received in

revised form

19.04.2019

Accepted

31.05.2019

\section{Corresponding \\ author:}

Oleksandr

Shevchenko

E-mail:

tmipt@ukr.net

\section{DOI:}

$10.24263 / 2304-$

974X-2019-8-2-

11

\section{Abstract}

Introduction. The paper concerns the determination of the relations of energy potentials in mass flows of gas and steam-gas systems and their changes in thermodynamic transformations and regeneration possibilities.

Materials and methods. Researches are presented in the form of phenomenological generalizations on the basis of the laws of chemistry, thermodynamics with thermochemical calculations based on Hess's law.

Results and discussion. Transformation of incoming gas streams used as the primary sources of chemical energy potentials with conversion into thermal energy is accompanied by losses at the level of heat of condensation of the formed vapor phase. Vapor-gas mixtures are generated in the processes of drying, aeration of grains for germination, in systems of aerobic fermentation processes, in the aeration of industrial wastewater, etc.

The course of such processes takes place in thermodynamic parameters, which do not correspond to similar characteristics of the environment, which is accompanied by energy losses at the levels of difference between their enthalpies. From this point of view, an important component of such gas-steam mixtures is the steam fraction of water, since it carries the thermal potential of vaporization.

The article discusses the ratio of parameters of material and heat flows, provides information that the energy potential of condensation of the vapor phase in products of combustion of gases is close to $10 \%$ of their calorific value.

The estimation of the prospects of the application of heat pipes in heat recovery systems by the creation of closed energy circuits is evaluated. It is shown the possibility of combining heat exchanging surfaces of cooling and heating with heat pipes, which achieve the same parameters of the temperature of evaporation and condensation of intermediate thermal agents, the thermodynamic parameters of the latter in terms of the possibility of their application in the systems being created are given.

With the presence of energy converters in the form of compressors and gas-expansion machines, the recovery systems are converted into local heat pumps.

The use of methane, ethane, propane and butane as the primary source in the formation of water vapor is carried out in quantities corresponding to their chemical formula, depending on the ratio of the number of atoms of carbon and hydrogen. Recuperative recovery of the energy of the output vapor-gas mixture is expedient to carry out in the direction of the input air flow in systems with an intermediate coolant and implementation of heat exchange processes with the simulation of effects of thermal pipes or with the addition to the schemes of heat pumps.

Conclusions. The schemes of thermodynamic processes confirm the possibilities of applying the proposed thermodynamic transformations. 


\section{Introduction}

Energy flows and their transformations in the processes of food technologies are, in most cases, associated with material flows that are carriers of the first [1]. At the same time, energy potentials in the form of the chemical energy of input flows of raw materials, semiproducts and finished products are the subject of the main interests of any technology [2]. Chemical and biochemical reactions associated with the transformation of material flows are accompanied by the release or absorption of energy [3]. More often, such energy is represented by heat and the magnitudes of thermal effects in thermochemical equations are represented by a "plus" sign in exothermic reactions and a "minus" sign for endothermic interactions [4].

In a significant number of technologies in food industries biochemical transformations of material flows in the directions of both resynthesis and synthesis of more complex substances are used. Forms of energy contained in different substances and released during chemical reactions or in the course of physical processes (for example, during condensation of steam or liquid crystallization), are defined as the internal energy of substance [5].

The thermal effects of such reactions depend on the nature of the inputs and reaction products, their aggregate state and temperature. The latter often values their energy potential, which deserves the full recovery and use at the levels of technologies of heat pumps [6, 7].

Modern studies are aimed at the prospects of using secondary low-potential heat resources [8], the creation of high-temperature heat pumps [9], the use of heat pipes in geothermal heat pump systems [10], the creation of combinations of heat pumps with solar energy utilization systems [11] and absorption-compression pumps [12]. The urgency of addressing the problems of the recuperation of secondary energy recourses is due to the fact that the industrial sector consumes one-third of the world energy with subsequent its transformation into thermal energy at the level of 50\% [7].

The purpose of the study was to determine the energy potential of the media formed as a result of the transformations of material flows with the formation of gas-steam mixtures and the prospects for their use.

\section{Materials and methods}

Research are presented in the form of analytical and phenomenological generalizations, based on the laws of chemistry and thermodynamics. Thermochemical calculations are performed on the basis of Hess's law, which determines that the thermal effects of the reactions depend only on the initial and final states of matter [13].

The used provisions are related to the laws of conservation and transformation of the mechanical and internal energy of systems, taking into account the equations of ideal and real gases, the first and second laws of thermodynamics, information about the thermodynamic parameters of refrigerant agents and the laws concerning energy and entropy balances.

\section{Results and discussion}

In modern conditions, the role of energy primary sources is often performed by representatives of a homologous series such as methane, ethane, propane and butane, the combustion of which leads to the formation of carbon dioxide and water in accordance with the reactions: 


$$
\begin{array}{cl}
\mathrm{CH}_{4}+2 \mathrm{O}_{2}=\mathrm{CO}_{2}+2 \mathrm{H}_{2} \mathrm{O} ; & 2 \mathrm{C}_{2} \mathrm{H}_{6}+7 \mathrm{O}_{2}=4 \mathrm{CO}_{2}+6 \mathrm{H}_{2} \mathrm{O} ; \\
\mathrm{C}_{3} \mathrm{H}_{8}+5 \mathrm{O}_{2}=3 \mathrm{CO}_{2}+4 \mathrm{H}_{2} \mathrm{O} ; & 2 \mathrm{C}_{4} \mathrm{H}_{10}+13 \mathrm{O}_{2}=8 \mathrm{CO}_{2}+10 \mathrm{H}_{2} \mathrm{O} .
\end{array}
$$

Let's turn to calculations of thermal effects. It is known that the heat of formation of "liquid" water is $285.8 \mathrm{~kJ} / \mathrm{mol}$ [14]. This means that the synthesis of $18 \mathrm{~g}$ of water from $2 \mathrm{~g}$ of hydrogen and $16 \mathrm{~g}$ of oxygen is accompanied by the release of $285.8 \mathrm{~kJ}$ of thermal energy. However, the heat of formation of water steam equals $241.8 \mathrm{~kJ} / \mathrm{mol}$, which corresponds to the thermochemical equation:

$$
\mathrm{H}_{2} \mathrm{O}_{2}+\frac{1}{2} \mathrm{O}_{2}=\mathrm{H}_{2} \mathrm{O}_{(s)}+241.8 \mathrm{~kJ} \text {. }
$$

It is obvious that the difference of $285.8-241.8=44 \mathrm{~kJ}$ is attributed to one mole (18 g) with the heat of evaporation of water at $25^{\circ} \mathrm{C}$.

The equation corresponds to the formation of carbon dioxide

$$
\mathrm{C}+\mathrm{O}_{2}=\mathrm{CO}_{2}+393.5 \mathrm{Kj} \text {. }
$$

The thermal effect of the methane oxidation reaction $\mathrm{CH}_{4}$ for the known heat of its formation $(74.9 \mathrm{~kJ} / \mathrm{mol})$ and its products of combustion - carbon dioxide $(393.5 \mathrm{~kJ} / \mathrm{mol})$ and water $(285.8 \mathrm{~kJ} / \mathrm{mol})$ is equal to

$$
\mathrm{CH}_{4}+2 \mathrm{O}_{2}=\mathrm{CO}_{2}+2 \mathrm{H}_{2} \mathrm{O}+(-74.9+393.5+571.6)=890.2 \mathrm{~kJ},
$$

which corresponds to Hess's law [15].

The ratio of the composition of hydrogen and carbon follows from the formula $\mathrm{C}_{n} \mathrm{H}_{2 n+2}$ where $\mathrm{n}$ is the number of carbon atoms comes out from the homologous series of saturated hydrocarbons.

Thus, the combustion of natural gases is accompanied by the formation of a mixture of $\mathrm{CO}_{2}$ and $\mathrm{H}_{2} \mathrm{O}$ in the form of the steam fraction of the latter, since its temperature is greater than $100{ }^{\circ} \mathrm{C}$ with energy losses at its thermal capacity. An important component in the latter is the proportion of the heat of steam formation of water, which can be turned to technological needs by condensation of water steam [16].

The dependencies (1)-(3) give the material relations on the basis of which the

\begin{tabular}{|c|c|c|c|c|}
\hline \multirow[b]{2}{*}{ System parameter } & \multicolumn{4}{|c|}{ Gas } \\
\hline & $\begin{array}{c}\text { Methane } \\
\mathrm{CH}_{4}\end{array}$ & Ethan $\mathrm{C}_{2} \mathrm{H}_{6}$ & $\begin{array}{c}\text { Propane } \\
\mathrm{C}_{3} \mathrm{H}_{8}\end{array}$ & $\begin{array}{c}\text { Butane } \\
\mathrm{C}_{4} \mathrm{H}_{10}\end{array}$ \\
\hline Molecular weight & 16 & 30 & 44 & 58 \\
\hline The ratio of the $\mathrm{N} / \mathrm{C}$ atoms & 4 & 3 & 2.67 & 2.5 \\
\hline Number of $\mathrm{H}_{2} \mathrm{O}$ at burning of & & & & \\
\hline $1 \mathrm{~kg}$ of gas, $\mathrm{kg}$ & 2.25 & 1.8 & 1.636 & 1.552 \\
\hline Heat of condensation of $\mathrm{H}_{2} \mathrm{O}, \mathrm{kJ}$ & 5081.4 & 4065.14 & 3694.8 & 3505 \\
\hline
\end{tabular}
calculations on the quantities of the generated steam and heat of its condensation are made (Table 1).

Table 1

Ratio of material and energy indicators

Obviously, the expediency of recuperative return of heat of condensation can be determined in comparison with the calorific value of gases. According to the known value of the theoretical indicator of this value for methane $890.2 \mathrm{~kJ} / \mathrm{mol}$, the conversion to $1 \mathrm{~kg}$ of its mass gives a value of $55108 \mathrm{~kJ}$. However, according to reference data, it is $49.800 \mathrm{~kJ} / \mathrm{kg}$, for propane it is 46.400 and for ethan it is $47.500 \mathrm{~kJ} / \mathrm{kg}$. This means that the indicator of the recuperative effect is approaching to $10 \%$ of the total indicator of calorific value [14].

Products of combustion of gases in the form of a mixture of $\mathrm{CO}_{2}$ and $\mathrm{H}_{2} \mathrm{O}$ as material flows simultaneously serve as energy streams. The efficiency of the use of the latter depends on the organization of heat transfer to other material flows and the thermodynamic parameters of such processes. 
From the point of view of the interests of the stability of the recuperative regimes of the return of heat of condensation it is expedient to consider the use of the heater of the income air flow. In this case, it is important the incoming air streams and outcome mixtures to be maximally synchronized.

In the classical schemes of installation of steam generators, the spent steam-gas mixture gives its energy potential for the heating of nutritious water in the economizer and in the air heater. However, for example, there are no economisers in the dryers for malt, and the installation of an air heater, in which there is a heat transfer between two significant streams of air gas-steam mixture, has noticeable complexity. The latter are related to the achievement of the calculated surface of the heat transfer and the limited temperature difference as driving factors. The use of the idea of a heat pipe corresponds to such option, which is accompanied by the presence in the system of an intermediate coolant with thermodynamic parameters in the regimes of phase transitions [17]. The achievement of these regimes in the evaporator and condenser depends on the thermodynamic characteristics of the intermediate coolants. In the tables 2 and 3 there are given the following characteristics for some substances that may be used in their role.

It follows from the data that the relationship between the pressures and temperatures of the refrigerants could satisfy the modes of phase transitions in the evaporator, but such upper limit as $50{ }^{\circ} \mathrm{C}$ limits the condensation temperature. However, in a system that is an analogue of a heat pipe, the phase transitions in the evaporator and the condenser should be carried out with minimal difference of temperature.

This analysis leads to the conclusion that the search for other substances for the role of the intermediate coolant is incomplete, and the achievement of satisfactory values of temperature variations is possible only with intervention to the thermodynamic cycle.

Table 2

Thermodynamic parameters of refrigerating agents

\begin{tabular}{|c|c|c|c|c|c|c|c|}
\hline Indicators & 爱 & 芯 &  & 壱 & 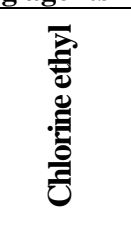 & 彭 & 芯 \\
\hline Chemical formula & $\mathrm{NH}_{3}$ & $\mathrm{C}_{4} \mathrm{H}_{10}$ & $\mathrm{CO}_{2}$ & $\mathrm{C}_{2} \mathrm{H}_{6}$ & $\mathrm{C}_{2} \mathrm{H}_{5} \mathrm{CCl}$ & $(\mathrm{CH})_{3} \mathrm{CH}$ & $\mathrm{C}_{3} \mathrm{H}_{8}$ \\
\hline Molecular weight & 17.032 & 58.1 & 44.005 & 30.058 & 64.51 & 58.1 & 44.079 \\
\hline $\begin{array}{l}\text { Volume mass of liquid, } \\
\mathrm{kg} / \mathrm{l}\end{array}$ & 0.6818 & 0.6 & $\begin{array}{l}\text { Non-liquid } \\
\text { at } 0.1 \mathrm{MPa}\end{array}$ & 0.5459 & 0.9232 & 0.6 & 0.5853 \\
\hline $\begin{array}{l}\text { Boiling temperature at } \\
0.1 \mathrm{MPa},{ }^{\circ} \mathrm{C}\end{array}$ & -33.35 & 0.6 & - & -88.3 & 13.1 & -13.3 & -44.5 \\
\hline Critical temperature, ${ }^{\circ} \mathrm{C}$ & 132.9 & 150.8 & 31.0 & 32.1 & 182.8 & 133.7 & 95.6 \\
\hline $\begin{array}{l}\text { Heat of steam generation } \\
\text { at } 0^{\circ} \mathrm{C}, \mathrm{kJ} / \mathrm{kg}\end{array}$ & 1257.8 & 388.4 & 231.3 & 328.5 & 401.4 & 388.4 & 376.7 \\
\hline $\begin{array}{l}\text { Value of heat capacities } \\
c_{p} / c_{v}\end{array}$ & 1.297 & 1.108 & 1.3003 & 1.224 & 1.1257 & 1.11 & 1.153 \\
\hline $\begin{array}{l}\text { Suction pressure at } \\
-10^{\circ} \mathrm{C}, \mathrm{MPa}\end{array}$ & 0.793 & 0.0738 & 2.71 & 1.88 & 0.0411 & 0.15 & 0.359 \\
\hline $\begin{array}{l}\text { Condensation pressure at } \\
30^{\circ} \mathrm{C}, \mathrm{MPa}\end{array}$ & 1.18 & 0.302 & 0.73 & 0.477 & 0.1905 & 0.46 & 1.119 \\
\hline $\begin{array}{l}\text { The pressure ratio at } \\
+30^{\circ} \mathrm{C} \text { in the condenser } \\
\text { and at }-10^{\circ} \mathrm{C} \text { in the } \\
\text { evaporator }\end{array}$ & 4.03 & 4.09 & 2.7 & 2.54 & 4.63 & 4.0 & 3.11 \\
\hline
\end{tabular}


Parameters of a saturated steam of refrigerators

\begin{tabular}{|c|c|c|c|c|c|c|c|}
\hline \multirow{2}{*}{$\begin{array}{c}\text { Absolute } \\
\text { pressure, } \\
\text { MPa }\end{array}$} & \multirow[b]{2}{*}{$\mathbf{t},{ }^{\circ} \mathbf{C}$} & \multicolumn{2}{|c|}{ Specific volume } & \multicolumn{2}{|c|}{ Specific enthalpy } & \multicolumn{2}{|c|}{ Specific entropy } \\
\hline & & $\begin{array}{c}\text { liquid } \\
\mathrm{V}^{\prime}, 1 / \mathrm{kg}\end{array}$ & $\begin{array}{c}\text { steam } \mathrm{V}^{\prime \prime}, \\
\mathrm{m}^{3} / \mathrm{kg}\end{array}$ & $\begin{array}{c}\text { liquid } \\
\mathrm{i}^{\prime}, \mathrm{kJ} / \mathrm{kg}\end{array}$ & $\begin{array}{c}\text { steam } \\
\mathrm{i}^{\prime \prime}, \mathrm{kJ} / \mathrm{kg}\end{array}$ & $\begin{array}{l}\text { liquid } \mathrm{S}^{\prime}, \\
\mathrm{kJ} /(\mathrm{kg} \cdot \mathrm{K})\end{array}$ & $\begin{array}{l}\text { steam S", } \\
\mathrm{kJ} /(\mathrm{kg} \cdot \mathrm{K})\end{array}$ \\
\hline \multicolumn{8}{|c|}{ Ammonia } \\
\hline 2.03 & 50 & 1.78 & 0.064 & 659 & 1712 & 4.99 & 8.25 \\
\hline 1.56 & 40 & 1.73 & 0.083 & 609 & 1711 & 4.83 & 8.35 \\
\hline 1.17 & 30 & 1.68 & 0.114 & 555 & 1706 & 4.66 & 8.47 \\
\hline 0.85 & 20 & 1.64 & 0.149 & 512 & 1700 & 4.52 & 8.57 \\
\hline 0.62 & 10 & 1.6 & 0.206 & 465 & 1692 & 4.35 & 8.69 \\
\hline 0.43 & 0.0 & 1.57 & 0.290 & 419 & 1682 & 4.19 & 8.81 \\
\hline 0.29 & -10 & 1.53 & 0.419 & 372 & 1671 & 4.02 & 8.95 \\
\hline 0.19 & -20 & 1.5 & 0.620 & 327 & 1657 & 3.84 & 9.10 \\
\hline 0.12 & -30 & 1.48 & 0.960 & 282 & 1642 & 3.66 & 9.26 \\
\hline 0.072 & -40 & 1.45 & 1.550 & 237 & 1626 & 3.47 & 9.44 \\
\hline 0.041 & -50 & 1.42 & 2.630 & 193 & 1610 & 3.28 & 9.63 \\
\hline \multicolumn{8}{|c|}{ Chladon-12 } \\
\hline 1.21 & 50 & 0.83 & 0.014 & 449 & 572 & 4.16 & 4.54 \\
\hline 0.96 & 40 & 0.80 & 0.018 & 439 & 568 & 4.13 & 4.55 \\
\hline 0.74 & 30 & 0.77 & 0.024 & 429 & 565 & 4.10 & 4.55 \\
\hline 0.57 & 20 & 0.75 & 0.031 & 419 & 561 & 4.07 & 4.55 \\
\hline 0.42 & 10 & 0.73 & 0.014 & 410 & 556 & 4.03 & 4.55 \\
\hline 0.309 & 0.0 & 0.72 & 0.056 & 400 & 552 & 4.00 & 4.56 \\
\hline 0.22 & -10 & 0.70 & 0.077 & 391 & 548 & 3.97 & 4.56 \\
\hline 0.151 & -20 & 0.69 & 0.109 & 381 & 543 & 3.93 & 4.57 \\
\hline 0.101 & -30 & 0.67 & 0.160 & 372 & 538 & 3.89 & 4.58 \\
\hline 0.064 & -40 & 0.66 & 0.242 & 363 & 534 & 3.86 & 4.59 \\
\hline 0.039 & -50 & 0.65 & 0.383 & 355 & 529 & 3.82 & 4.60 \\
\hline
\end{tabular}

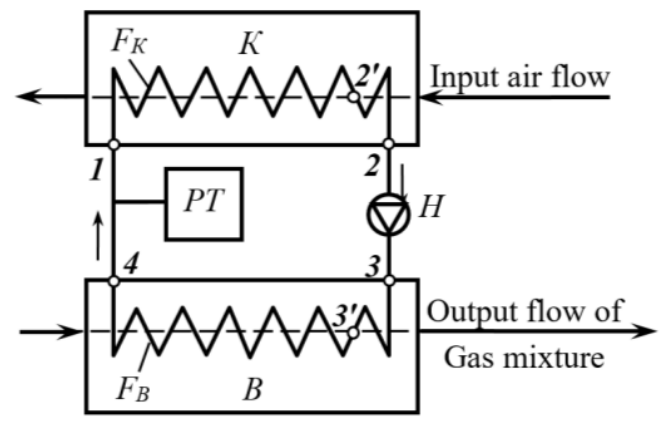

Figure 1. Scheme of the contour of the intermediate coolant:

$\mathrm{B}$ - evaporator; $\mathrm{K}$ - capacitor; $\mathrm{RT}$ - pressure regulator; $\mathrm{H}$ - pump; FK - heat transfer surface of condenser; $\mathrm{FV}$ - surface of the heat transfer of the evaporator
In Figure 1 it is a schematic diagram of the internal coolant for contour system in which the return of the condensate can be achieved at the expense of gravitational forces or forced by the use of the pump (Patent of Ukraine 14523). For identical pressures on the heat transfer surfaces of the condenser and evaporator, the temperature of the steam phase in them will be the same. 
Depending on the intensity of the heat transfer processes in the condenser, the condensate may leave it at a temperature of the steam phase or lower. The processes shown in Figure 2 in coordinates of T-s correspond to these two cases. To intensify the heat exchange, it is expedient to limit the area of condensate overcooling.

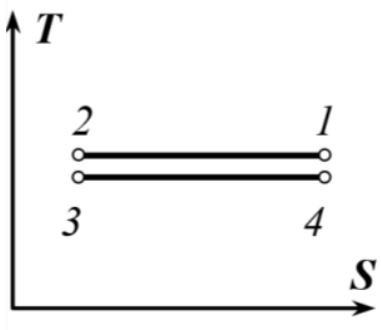

$a$

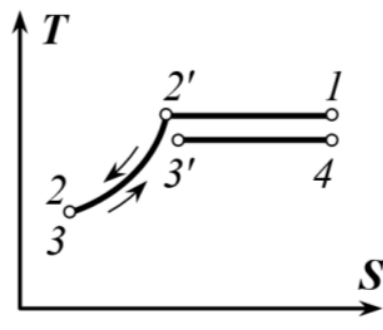

$b$

Figure 2. Diagrams of processes:

a - without re-cooling of the condensate:

1-2 - condensation of steam; 3-4 - formation of the steam phase in the evaporator; $\mathrm{b}$ - with supercooling and post-heating of condensate:

1-2' - condensation of steam; 2'-2 - overcooling of the condensate;

$3-3^{\prime}$ - post-heating of condensate; $3-4$ - formation of the steam phase in the evaporator

Further improvement of systems is connected with the forced transformation of steam of intermediate coolant due to changes in pressures in the system. For this, the contour is supplemented by a compressor and a regulator valve or a gas-expansion machine on the return section (Figure 3).

Case in the Figure 3 refers to the use of a steam-liquid intermediate coolant, and a scheme in the Figure 3, $b$ refers to gas intermediate coolant.

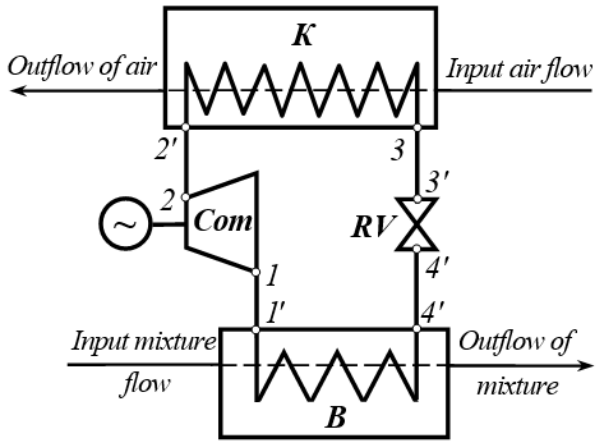

$a$

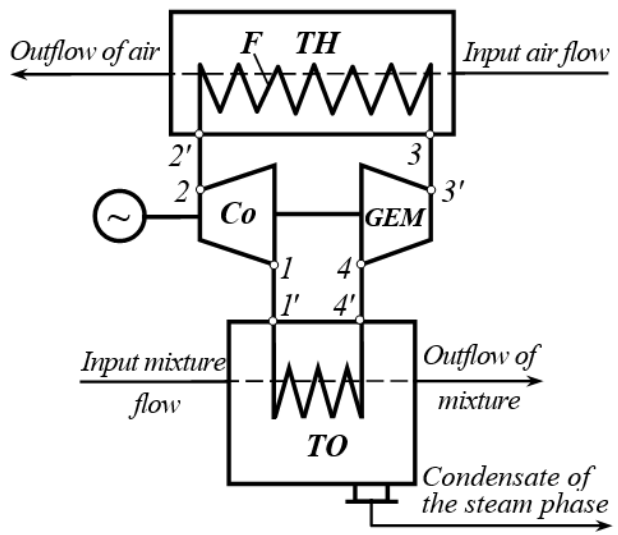

$b$

Figure 3. Schemes of devices with transformers of thermodynamic parameters of the steam phase: a - with compressor Com and regulator valve $R V$; b - with compressor Com and gas-expansion machine GEM

The presence of an intermediate compression of the steam or gas phase means an increase 
in their temperature. Due to the limited time of the processes of compression, they will be considered to be adiabatic as well as processes of throttling of condensate in the regulator valve and in gas-expansion machine.

Addition of the scheme in Figure 3 a, with compressor and regulator valve transforms the device into a device with characteristics of a heat pump. The processes occurring in it are reflected in Figure 4 in coordinates T-s.

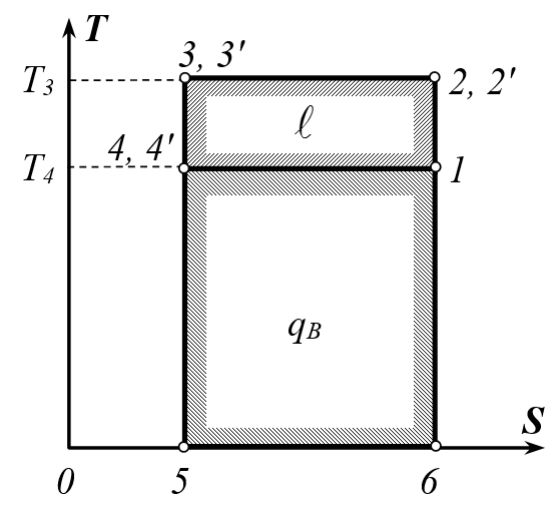

\section{Figure 4. Scheme of the thermodynamic cycle in the coordinates T-s: 1-2 - adiabatic compression of the steam phase; $2 '-3$ - condensation of the steam; 3'-4 - throttle of condensate; 4'-1' - formation of the steam phase}

The compression of the steam of the intermediate coolant means that condensation and formation of the steam phase occur at different pressures and temperatures. Obviously, this creates conditions for increasing the temperature of the ouflow from the condenser in favor of increasing the overall efficiency of the system. The areas in the diagram (Figure 4) reflect the energy contribution of various components.

The area 1-4-5-6-1 reflects the amount of thermal energy selected from the outflow of the gas-steam mixture, the area 1-2-3-4-1 represents the amount of energy introduced into the system by the compressor.

The thermal energy transmitted to the input air stream is shown in the diagram with an area of 1-2-3-4-5-6-1. It is obvious that the proportion of thermal energy, which is selected from the outflow of the gas mixture, must essentially exceed the proportion of energy introduced into the system from the compressor.

As in the case of reflection of the analytical relations of theoretical cycles of heat pumps, in the study of this scheme, there are dependencies

$$
q_{c}=q_{e}+\ell, \mathrm{kJ} / \mathrm{kg},
$$

where $\mathrm{q}_{\mathrm{c}} \mathrm{i} \mathrm{q}_{\mathrm{e}}$ - specific heat load per unit mass of the coolant in the condenser and evaporator respectively; $\ell$ - specific energy introduced into the system by a compressor.

The work of adiabatic compression of ateam of the intermediate coolant in specific calculation is determined by the dependence:

$$
\ell=\frac{R}{k-1}\left(T_{2}-T_{1}\right), \mathrm{kJ} / \mathrm{kg},
$$


where $\mathrm{R}$ - universal gas constant, $\mathrm{J} /(\mathrm{kg} \cdot \mathrm{K}) ; \mathrm{k}$ - adiabatic indicator.

To determine total energy consumption, it is necessary to find the magnitude of the flow of the intermediate coolant circulating in the circuit.

At the known temperature of the input air flow at the entrance to the heater $t_{i n 1}$ and at the output of it $t_{i n 2}$, the power of the required energy flow should be

$$
Q_{\text {con }}=c_{a} m_{\text {air }}\left(t_{i n 1}-t_{i n 2}\right), \mathrm{kW},
$$

where $\mathrm{c}_{\mathrm{a}}$ - the heat capacity of air, adopted as the constant value, $\mathrm{kJ} /(\mathrm{kg} \cdot \mathrm{K}) ; \mathrm{m}_{\text {air }}-$ mass flow of air, $\mathrm{kg} / \mathrm{s}$.

Herewith

$$
Q_{c o n}=Q_{e v}+L, \mathrm{~kW}
$$

where $\mathrm{Q}_{\mathrm{ev}}$ - the power of the heat flow from the evaporator, $\mathrm{kW} ; \mathrm{L}$ - power of the heat flow introduced by the compressor, $\mathrm{kW}$.

Hence the theoretical load on the evaporator

$$
Q_{e v}=Q_{c o n}-L, \mathrm{~kW}
$$

The energy flux of the evaporator is transferred by the intermediate coolant in the state of the steam phase, and therefore its mass flow is determined by the condition

$$
m_{i . c}=\frac{Q_{e v}}{r}=\frac{Q_{c o n}-L}{r}, \mathrm{~kg} / \mathrm{s},
$$

where $\mathrm{r}$ - specific heat of vaporization of intermediate coolant.

\begin{tabular}{|c|c|}
\hline $\begin{array}{c}\text { Temperature, } \\
{ }^{\circ} \mathrm{C}\end{array}$ & $\begin{array}{c}\text { Mass heat capacity } \\
\text { of air, } \mathrm{kJ} /(\mathrm{kg} \cdot \mathbf{K})\end{array}$ \\
\hline 0 & 1.0036 \\
\hline 100 & 1.0061 \\
\hline 200 & 1.0115 \\
\hline 300 & 1.0191 \\
\hline 400 & 1.0283 \\
\hline 500 & 1.0387 \\
\hline
\end{tabular}

To estimate the relations of mass flows, we will make corresponding calculations.

Although earlier it was noted that the heat capacity of the air is assumed to be constant, we still give data relating to this value in the range of temperatures from 0 to $500{ }^{\circ} \mathrm{C}$ :

Declining values $\mathrm{c}_{\mathrm{pm}}$ in the specified range is about $3.5 \%$ and evaluating the temperature values as $t_{i n 1}=0$ та $t_{i n 2}=200{ }^{\circ} \mathrm{C}$, we accept $\mathrm{c}_{\mathrm{pm}}=1.006 \mathrm{~kJ} /(\mathrm{kg} \cdot \mathrm{K})$. Then specific costs are calculated on a mass flow $m_{\text {air }}=1 \mathrm{~kg} / \mathrm{s}$ will be

$$
\mathrm{Q}_{\mathrm{con}}=1.006 \cdot 1,0 \cdot 200=201.2 \mathrm{~kW} \text {. }
$$

Let's assume that the energy contribution of the compressor is $10 \%$ from $\mathrm{Q}_{\text {con. }}$. Then

$$
\mathrm{Q}_{\mathrm{ev}}=201.2-20.12=181.08 \mathrm{~kW} \text {. }
$$


The specific heat of vaporization of an intermediate coolant will be taken at a level of $2200 \mathrm{~kJ} / \mathrm{kg}$ and then its mass flow will be

$$
m_{i . c}=\frac{181.08}{2200}=0.082, \mathrm{~kg} / \mathrm{s}
$$

To calculate the volumetric flows of the steam phase of the intermediate coolant, we turn to the corresponding ratios at different pressures related to the saturated steam:

\begin{tabular}{|c|c|}
\hline $\begin{array}{c}\text { Pressure of steam, } \\
\mathbf{M P a}\end{array}$ & $\begin{array}{c}\text { Specific volume } \\
\text { of steam } \mathbf{~}^{\mathbf{\prime}}, \mathbf{~}^{\mathbf{3}} \mathbf{/ k g}\end{array}$ \\
\hline 0.101 & 1.673 \\
0.19854 & 0.8917 \\
0.313 & 0.582 \\
0.4155 & 0.4461 \\
0.476 & 0.3926 \\
\hline
\end{tabular}

For the obtained data and at $m_{i . c}=0.082, \mathrm{~kg} / \mathrm{s}$ volumetric flows are determined by the dependence

$$
v_{i . c}^{\prime}=m_{i . c} v^{\prime \prime}
$$

where $\mathrm{v}^{\prime \prime}$ - specific volume of steam, $\mathrm{m}^{3} / \mathrm{kg}$.

According to these pressures they will br $0.1372 ; 0.0731 ; 0.0477 ; 0.0366 ; 0.0322 \mathrm{~m}^{3} / \mathrm{s}$.

Accepting the velocity of the steam phase of the intermediate coolant $\mathrm{w}=50 \mathrm{~m} / \mathrm{s}$, we determine the geometric parameters of the cross-section of the pipelines:

$$
f=\frac{v_{i . c}^{\prime}}{w} ; \quad d=\sqrt{\frac{4 v_{i . c}^{\prime}}{\pi w}}
$$

where $\mathrm{f}$ - the cross-section of the pipeline; $\mathrm{d}$ - pipeline diameter.

For a number of obtained values $v_{i . c}^{\prime}$ we get the appropriate number of diameters:

$$
\mathrm{d}=0.059 ; 0.043 ; 0.0349 ; 0.0305 ; 0.0286 \mathrm{~m} \text {. }
$$

For the possibility of using machine calculations, we give a generalized formula for determining the diameter $\mathrm{d}$ :

$$
d=2 \sqrt{\frac{0.9 c_{a} m_{a i r}\left(t_{i n 1}-t_{i n 2}\right)}{\pi r} \cdot \frac{v^{\prime \prime}}{w}}=1.0707 \sqrt{\frac{c_{a} m_{a i r}\left(t_{i n 1}-t_{i n 2}\right)}{r} \cdot \frac{v^{\prime \prime}}{w}} .
$$

From the obtained values of the diameters, it is possible to conclude that in terms of constructive solutions, they are quite acceptable. Similar results are quite expected taking into account the high levels of heat flows transmitted by heat pipes. The reduction of elements into the system, which transform it into a heat pump, means that it can be used in the 
conditions of the limited values of the output flow temperatures.

The latter may be suitable for dryers in which the initial material flows are doubled.

One of these outflows is a gas-steam mixture produced by the combustion of the primary energy carrier, and another is an exhaust-drying agent, which is formed by heating the air flow by its interaction with the medium. In the latter case, depending on the design solution and technological regimes at the relatively high temperature potentials of the isoenthalipic processes of drying temperature characteristics can be limited. Such ratios make it possible to estimate such flows as low-potential ones.

Scheme in Fig 3, b concerns the case when gas circulating in a circuit without phase transitions acts as an intermediatecoolant. Under these conditions, the driving factor of heat transfer in the heat exchanger-heater HEH and the heat exchanger-cooler HEC increases due to diabatic compression of gas in the compressor and additional cooling by adiabatic expansion in gas-expansion machine, respectively.

The presence of a sealed cooling surface in the heat exchanger HEC means the possibility of condensation of the steam phase from a mixture of gases in favor of increasing the level of recovery energy return into the inflow of air.

The heat transfer in the heat exchanger HEH in the direction from the intermediate heat carrier to the input air stream is accompanied by a decrease in the temperature of the first in the direction from point 2 to point 3 . Depending on the construction of the transport elements of the heat transfer surface $F$, the pressure in it can be stabilized or will decrease.

If in the preceding case (Figure 4) isotherms 2-3 and 4-1 are simultaneously isobars, then according to the scheme in Figure 3, b such coincidence is not obligatory. The diagram of the thermodynamic cycle for this case is shown in Figure 5 and 6.

The area 4-1-6-5-4 reflects the amount of heat perceived in the HEC, the area 1-2-3-4 is the amount of energy introduced into the stream by the compressor, and transferred to the air flow in $\mathrm{HEH}$ thermal energy, equivalent to the area of 1-2-3-4-5-6-1.

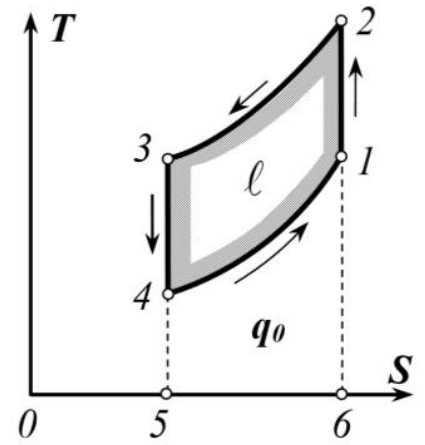

Figure 5. Scheme of the thermodynamic cycle in the coordinates $T$-s for the case in the scheme of Figure 3, b:

1-2 - adiabatic compression of the intermediate heat-carrier in the compressor; 2-3 - polytropic cooling;

3-4 - adiabatic expansion in gas-expansion machine;

4-1 - polytropic heating in the HEC

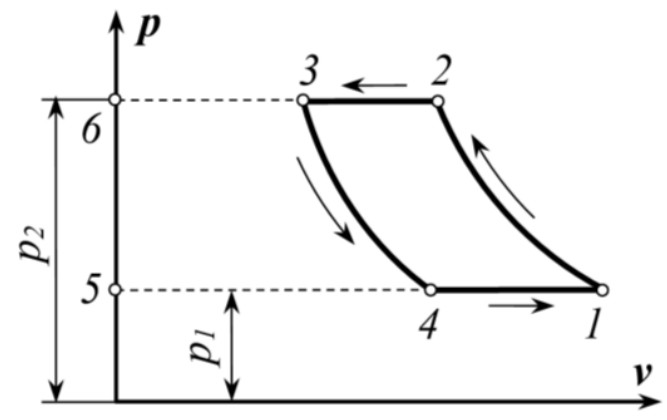

Figure 6. Scheme of the thermodynamic cycle in the coordinate's p-v for the case in the scheme of

Figure 3, b:

1-2 - adiabatic compression of an intermediate coolant in a compressor;

2-3 - isobaric cooling;

3-4 - adiabatic expansion in gas-expansion machine; 4-1' - isobaric heating of the intermediate coolant in the HEC 
For the isobaric processes heat transfer processes in the heat exchangers HEH and HEC the diagram of the thermodynamic cycle in the coordinates $\mathrm{p}-\mathrm{v}$ is shown in Figure 6.

The area 1-2-3-6-5-4-1 in this diagram shows the compression energy of the compressor, and the area 3-6-5-4-3 - the work received in gas-expansion machine. The amount of thermal energy subtracted from the output stream:

$$
q_{0}=c_{p m}\left(T_{1}-T_{4}\right) \text {, }
$$

where $\mathrm{c}_{\mathrm{pm}}$ - average mass heat capacity at constant pressure.

The energy entering to the cycle by the compressor,

$$
\ell=c_{p m}\left(T_{2}-T_{1}\right) \text {. }
$$

The energy returned by the gas-expansion machine to compressor,

$$
\ell_{\text {gem }}=c_{p m}\left(T_{3}-T_{4}\right) \text {. }
$$

The mass flow of the intermediate coolant is

$$
m_{i . c}=\left(Q_{T H}-L\right) / q_{0},
$$

where $\mathrm{Q}_{\mathrm{TH}}$ - the power of the heat flow, transmitted to the inlet air flow in HEH; L - power of the power flow of the gas-expansion machine.

The disadvantage of the system with gas intermediate coolant is the relatively low heat capacity of the gas.

\section{Conclusions}

The performed researches allow to note the following.

1. The use of such representatives of the homologous series as methane, ethane, butane and propane as energy primary sources leads to the formation of water steam in quantities corresponding to their chemical formulas, depending on the ratio of the numbers of carbon and hydrogen atoms in the compounds.

With the decrease of the molecular mass of gases for identical mass flows, taking part in energy transformations, the amount of water steam increases.

2. A mixture of carbon dioxide and water steam in products of combustion is characterized by the energy potential of condensation of the latter at levels of about $10 \%$ of the calorific value of gases. Hence the expediency of creating systems for the recovery return of the thermal potential of the steam phase.

3. The achievement of modes of condensation of water steam and the separation of condensate from the steam-gas mixture means the need to cool the latter to temperatures below $100^{\circ} \mathrm{C}$ for the implementation of this process at pressures close to atmospheric. This means that such a heat transfer simultaneously will allow to make deep utilization of the thermal energy of carbon dioxide as a component of the mixture.

4. Recuperative return of energy of the output steam-gas mixture should be carried out in the direction of the input air flow in systems with an intermediate coolant and the implementation of heat transfer processes simulating the effects of the heat pipe or with the addition of the schemes of heat pumps. The analysis of the thermodynamic cycles of the latter indicates that water can be used as an intermediate thermal agent that operates in phase transition modes. 


\section{References}

1. George Kosmadakis (2019), Estimating the potential of industrial (high-temperature) heat pumps for exploiting waste heat in EU industries, Applied Thermal Engineering, 156(25), pp. 287-298, DOI: 10.1016/j.applthermaleng.2019.04.082

2. Wang J.F., Brown C., Cleland D.J. (2018), Heat pump heat recovery options for food industry dryers, International Journal of Refrigeration, 86, pp. 48-55, DOI: 10.1016/j.ijrefrig.2017.11.028

3. Feng Huang, Zie Zheng, J.M.Baleynaud, Jun Lu (2017), Heat recovery potentials and technologies in industrial zones, Journal of the Energy Institute, 90(6), pp. 951-961, DOI: 10.1016/j.joei.2016.07.012

4. Omid Ashrafi, Serge Bedard, Bahador Bakhtiari, Bruno Poulin (2015), Heat recovery and heat pumping opportunities in a slaughterhouse, Energy, 89, pp. 1-13, DOI: 10.1016/j.energy.2015.05.129

5. Bin Hu, Shengzhi Xu, R.Z.Wang, Hua Liu, Luyao Han, Zhiping Zhang, Hongbo Li (2019), Investigation on advanced heat pump systems with improved energy efficiency, Energy Conversion and Management, 192(15), pp. 161-170, DOI: 10.1016/j.enconman.2019.04.031

6. Paul Byrne, Redouane Ghoubali (2019), Exergy analysis of heat pumps for simultaneous heating and cooling, Applied Thermal Engineering, 149, pp. 414-424, DOI: 10.1016/j.applthermaleng.2018.12.069

7. Elliot Woolley, Yang Luo, Alessandro Simeone (2018), Industrial waste heat recovery: A systematic approach, Sustainable Energy Technologies and Assessments, 29, pp. 50-59, DOI: $10.1016 /$ j.seta.2018.07.001

8. Xu Z.Y., Wang R.Z., Chun Yang (2019), Perspectives for low-temperature waste heat recovery, Energy, 176, pp. 1037-1043, DOI: 10.1016/j.energy.2019.04.001

9. Bamigbetan R.Z., Eikevik T.M., Neksa P., Bantle P., Schlemminger C. (2019), The development of a hydrocarbon high temperature heat pump for waste heat recovery, Energy, 173, pp. 1141-1153, DOI: 10.1016/j.energy.2019.02.159

10. Hyunjeong Lim, Chanjoong Kim, Yeonjoo Cho, Minsung Kim (2017), Energy saving potentials from the application of heat pipes on geothermal heat pump system, Applied Thermal Engineering, 126, pp. 1191-1198,

DOI: 10.1016/j.applthermaleng.2017.04.086

11. Guo-Hua Shi, Lu Aye, Dan Li, Xian-Jun Du (2019), Recent advances in direct expansion solar assisted heat pump systems: A review, Renewable and Sustainable Energy, 109, pp. 349-366, DOI: 10.1016/j.rser.2019.04.044

12. Markmann B., Tokan T., Loth M., Stegmann J., Hartmann K.-H., Kruse H., Kabelac H. (2019), Experimental results of an absorption-compression heat pump using the working fluid ammonia/water for heat recovery in industrial processes, International Journal of Refrigeration, 99, pp. 59-68, DOI: 10.1016/j.ijrefrig.2018.10.010

13. Shaowei Chai, Xiangyu Sun, Yao Zhao, Yanjun Dai (2019), Experimental investigation on a fresh air dehumidification system using heat pump with desiccant coated heat exchanger, Energy, 171, pp. 306-314, DOI: 10.1016/j.energy.2019.01.023

14. But S.A. (2016), Udoskonalennya protsesiv i obladnannya u vyrobnytstvi solidiv ta pyva: monohrafiya, Kondor-Vydavnytstvo, Kyiv.

15. Nykytenko N.Y., Snezhkyn YU.F., Sorokovaya N.N. (2001), Matematychna model' i metod rozrakhunku teplomassoperenosa i fazovykh prevrashchenyy v protsesakh sushky, Promyshlennaya teplotekhnyka, 23(3), pp. 65-73.

16. Sokolenko A.I. et al. (2011), Intensyfikatsiya teplomasoobminnykh protsesiv $v$ kharchovykh tekhnolohiyakh, Feniks, Kyiv.

17. Snezhkin Yu.F. et al. (2008), Teplovi nasosy v systemakh teplokholodopostachannya, Naukova dumka, Kyiv. 